\title{
STRATEGI PENGEMBANGAN HASIL HUTAN BUKAN KAYU UNGGULAN DI KABUPATENKAMPAR - RIAU
}

\author{
Eni Suhesti, Hadinoto, Muhammad Ikhwan \\ Staff Pengajar Fakultas Kehutanan Universitas Lancang Kuning \\ JIn. Yos Sudarso Km. 8 Rumbai Pekanbaru Riau \\ Email : hesti1170@yahoo.co.id, hdinto@yahoo.co.id,mmighwan@yahoo.com.
}

\begin{abstract}
This study aims to 1) identify the types of NTFP and the level of excellence in Kampar District, 2) Formulate a potential HHBK development strategy to be excellent in Kampar District. The study was conducted on May-August 2016, with survey method. Data collection is done on three objects that are potential areas of NTFP, community and related offices. The data collection on the potential of NTFPs and the determination of the level of excellence of each type of HHBK shall be guided by the Minister of Forestry Regulation No.P.21 / Menhut-Il / 2009. The results of the study identified the types of HHBK in Kampar Regency there are 9 types, namely: honey (from Apis dorsata), rattan (Calamus sp), durian (Durio zibethinus), mangosteen (Garcinia mangostana), tampui (Bacaurea macrocarpa) Scaphium macropodum), Pinang (Areca catechu), petai (Parkia speciosa) and gaharu (Aqularia malaccensis), with HHBK excellence class including class II and class III. Development strategy of superior HHBK of Kampar Regency: 1) Improvement of product quality and diversification (honey and durian); 2) Increasing the quality of rural human resources; 3) Strengthening of rural institutions; 4) Facilities / business capital development, post-harvest handling and marketing
\end{abstract}

Keywords: Non-Timber Forest Products (HHBK), Kampar Kiri Sub-District, Gunung Sahilan Sub-District, Community Welfare.

\section{PENDAHULUAN}

Salah satu kekayaan negara kita adalah hutan yang tersebar di seluruh wilayah Indonesia, yang memiliki keanekaragaman yang tinggi baik berupa hasil hutan kayu maupun hasil hutan bukan kayu (HHBK). HHBK merupakan salah satu sumberdaya hutan yang memiliki keunggulan komparatif dan bersinggungan langsung dengan kehidupan masyarakat di sekitar hutan, dengan nilai kontribusi bagi perekonomian yang semakin meningkat dari tahun ke tahun (Moko H 2008). Oleh karena itu, Pemerintah Republik Indonesia telah mengeluarkan peraturan untuk pengembangan HHBK tersebut, melalui Peraturan Menteri Kehutanan RI No.P.19/Menhut-I//2009 tentang Strategi Pengembangan Hasil Hutan 
Bukan Kayu Nasional dan Peraturan Menteri Kehutanan RI No.P.21/MenhutI/2009 tentang Kriteria dan Indikator Penetapan Jenis Hasil Hutan Bukan Kayu Unggulan.

Strategi pengembangan HHBK unggulan secara nasional akan berhasil apabila pengembangannya di setiap daerah dijalankan dengan baik. Untuk itu diperlukan data dari masing-masing daerah provinsi maupun kabupaten tentang HHBK yang akan dijadikan sebagai unggulan daerah. Salah satu daerah di Provinsi Riau yang masih memiliki sumberdaya hutan yang relatif masih banyak dan masyarakatnya masih banyak yang memanfaatkan HHBK dari hutan di sekitarnya adalah Kabupaten Kampar. Dengan diketahuinya jenis-jenis HHBK yang berpotensi untuk menjadi komoditas unggulan untuk meningkatkan kesejahteraan masyarakat setempat, maka akan dapat disusun strategi pengembangannya sesuai dengan kondisi biofisik, sosial, ekonomi dan budaya daerah tersebut dan selanjutnya usaha budidaya dan pemanfaatannya dapat dilakukan secara lebih terencana dan terfokus serta berkelanjutan.

Penelitian ini bertujuan untuk: 1) mengidentifikasi jenis-jenis HHBK dan tingkat keunggulannya di Kabupaten Kampar, 2) Merumuskan strategi pengembangan HHBK yang potensial menjadi unggulan di Kabupaten Kampar

\section{METODE PENELITIAN}

Penelitian ini dilaksanakan di Kabupaten Kampar pada bulan MeiAgustus 2016. Metode penelitian adalah dengan metode survey. Pengambilan data dilakukan terhadap tiga objek yaitu kawasan yang berpotensi terdapat HHBK, masyarakat dan dinas terkait. Kawasan berpotensi yang dimaksud merupakan kawasan yang memilki potensi HHBK unggulan. Masyarakat dalam hal ini merupakan masyarakat yang berhubungan dengan kegiatan HHBK. Dinas-dinas terkait merupakan dinas yang menangani halhal yang berhubungan dengan kegiatan HHBK, yaitu Dinas Kehutanan dan Kesatuan Pengelolaan Hutan Produksi (KPHP) Kampar Kiri.

\section{Pengumpulan Data}

Data yang dikumpulkan terdiri dari data primer dan data sekunder. Data primer dikumpulkan dengan cara wawancara kepada masyarakat terpilih (key informan), yaitu masyarakat yang mengetahui HHBK yang banyak 
digunakan oleh masarakat, tata kelola HHBK tersebut sampai ke pemasarannya. Wawancara tersebut dilakukan dengan bantuan daftar pertanyaan dan wawancara secara mendalam. Pengambilan data primer ini juga dilakukan dengan cara observasi atau pengamatan kondisi HHBK di lapangan. Data dan variabel yang diamati dan dianalisis dalam penelitian meliputi: potensi biofisik dan lingkungan, teknologi, ekonomi, sosial, dan kelembagaan. Sedangkan data sekunder yang dikumpulkan merupakan data yang terkait dan mendukung untuk keperluan analisis penetapan unggulan. Data primer yang diperlukan dalam penelitian ini seperti yang tercantum pada Tabel 1.

Tabel 1. Data Yang Diperlukan Dalam Identifikasi Potensi Pengembangan HHBK Unggulan

\begin{tabular}{|c|c|c|c|c|}
\hline $\begin{array}{l}\mathbf{N} \\
\mathbf{O}\end{array}$ & $\begin{array}{l}\text { Data yang } \\
\text { diperlukan }\end{array}$ & $\begin{array}{l}\text { Parameter yang } \\
\text { diukur/ diamati }\end{array}$ & Sumber Data & $\begin{array}{c}\text { Metode } \\
\text { Pengumpulan } \\
\text { Data }\end{array}$ \\
\hline \multirow[t]{6}{*}{ I } & \multicolumn{4}{|c|}{ Biofisik \& Lingkungan } \\
\hline & - Potensi tanaman & Kelimpahan & $\begin{array}{l}\text { Kawasan hutan \& } \\
\text { non hutan }\end{array}$ & $\begin{array}{l}\text { Observasi } \\
\text { Lapangan }\end{array}$ \\
\hline & - Penyebaran & Sebaran komoditas & $\begin{array}{l}\text { Kawasan hutan \& } \\
\text { non hutan }\end{array}$ & $\begin{array}{l}\text { Observasi } \\
\text { Lapangan }\end{array}$ \\
\hline & - Status Konservasi & Status konservasi & BBKSDA/CITES & $\begin{array}{l}\text { Wawancara \& } \\
\text { Studi Pustaka }\end{array}$ \\
\hline & - Budidaya & Budidaya & $\begin{array}{l}\text { Kawasan non } \\
\text { hutan }\end{array}$ & $\begin{array}{l}\text { Observasi } \\
\text { Lapangan }\end{array}$ \\
\hline & $\begin{array}{l}\text { - Aksesibilitas ke } \\
\text { HHBK }\end{array}$ & Aksesibilitas & $\begin{array}{l}\text { Kawasan hutan \& } \\
\text { non hutan }\end{array}$ & $\begin{array}{l}\text { Observasi } \\
\text { Lapangan }\end{array}$ \\
\hline \multirow[t]{3}{*}{ II } & \multicolumn{4}{|l|}{ Teknologi } \\
\hline & - Teknologi Budidaya & Teknologi budidaya & Masyarakat & $\begin{array}{l}\text { Observasi } \\
\text { Lapangan }\end{array}$ \\
\hline & $\begin{array}{l}\text { - Teknologi } \\
\text { Pengolahan Hasil }\end{array}$ & Pengolahan hasil & Masyarakat & $\begin{array}{l}\text { Observasi } \\
\text { Lapangan }\end{array}$ \\
\hline \multirow[t]{4}{*}{ III } & \multicolumn{4}{|l|}{ Ekonomi } \\
\hline & $\begin{array}{l}\text { - Nilai perdagangan } \\
\text { ekspor }\end{array}$ & Nilai ekspor & $\begin{array}{l}\text { Dinas Perindustrian } \\
\text { \& Perdagangan } \\
\text { dan dinas terkait }\end{array}$ & $\begin{array}{l}\text { Wawancara \& } \\
\text { Studi Pustaka }\end{array}$ \\
\hline & $\begin{array}{l}\text { - Nilai perdagangan } \\
\text { lokal }\end{array}$ & $\begin{array}{l}\text { Nilai perdagangan } \\
\text { lokal }\end{array}$ & $\begin{array}{l}\text { Dinas Perindustrian } \\
\text { \& Perdagangan } \\
\text { dan dinas terkait }\end{array}$ & $\begin{array}{l}\text { Wawancara \& } \\
\text { Studi Pustaka }\end{array}$ \\
\hline & - Lingkup pemasaran & Lingkup pemasaran & $\begin{array}{l}\text { Dinas Perindustrian } \\
\text { \& Perdagangan } \\
\text { dan dinas terkait }\end{array}$ & $\begin{array}{l}\text { Wawancara \& } \\
\text { Studi Pustaka }\end{array}$ \\
\hline
\end{tabular}




\begin{tabular}{|c|c|c|c|c|}
\hline $\begin{array}{l}\mathbf{N} \\
\mathbf{0}\end{array}$ & $\begin{array}{l}\text { Data yang } \\
\text { diperlukan }\end{array}$ & $\begin{array}{l}\text { Parameter yang } \\
\text { diukur/ diamati }\end{array}$ & Sumber Data & $\begin{array}{c}\text { Metode } \\
\text { Pengumpulan } \\
\text { Data }\end{array}$ \\
\hline & $\begin{array}{l}\text { - Potensi pasar } \\
\text { internasional }\end{array}$ & $\begin{array}{l}\text { Potensi pasar } \\
\text { internasional }\end{array}$ & $\begin{array}{l}\text { Dinas Perindustrian } \\
\text { \& Perdagangan } \\
\text { dan dinas terkait }\end{array}$ & $\begin{array}{l}\text { Wawancara \& } \\
\text { Studi Pustaka }\end{array}$ \\
\hline & $\begin{array}{l}\text { - Mata rantai } \\
\text { pemasaran }\end{array}$ & Mata rantai & $\begin{array}{l}\text { Dinas Perindustrian } \\
\text { \& Perdagangan } \\
\text { dan dinas terkait }\end{array}$ & $\begin{array}{l}\text { Wawancara \& } \\
\text { Studi Pustaka }\end{array}$ \\
\hline & $\begin{array}{l}\text { - Cakupan } \\
\text { pengusahaan }\end{array}$ & Cakupan usaha & $\begin{array}{l}\text { Dinas Perindustrian } \\
\text { \& Perdagangan } \\
\text { dan dinas terkait }\end{array}$ & $\begin{array}{l}\text { Wawancara \& } \\
\text { Studi Pustaka }\end{array}$ \\
\hline & - Investasi usaha & investasi & $\begin{array}{l}\text { Badan penanaman } \\
\text { modal dan instansi } \\
\text { terkait }\end{array}$ & $\begin{array}{l}\text { Wawancara \& } \\
\text { Studi Pustaka }\end{array}$ \\
\hline \multirow[t]{3}{*}{ IV } & Sosial & & & \\
\hline & $\begin{array}{l}\text { - Pelibatan } \\
\text { masyarakat }\end{array}$ & $\begin{array}{l}\text { Keterlibatan } \\
\text { masyarakat }\end{array}$ & Masyarakat & Wawancara \\
\hline & - Kepemilikan Usaha & $\begin{array}{l}\text { Proporsi Modal } \\
\text { usaha }\end{array}$ & $\begin{array}{l}\text { Masyarakat \& } \\
\text { dinas terkait }\end{array}$ & Wawancara \\
\hline \multirow[t]{7}{*}{$\mathbf{V}$} & Kelembagaan & & & \\
\hline & $\begin{array}{l}\text { - Jumlah Kelompok } \\
\text { usaha produsen/ } \\
\text { koperasi } \\
\end{array}$ & Jumlah Kelompok & Masyarakat & Wawancara \\
\hline & $\begin{array}{l}\text { - Asosiasi Kelompok } \\
\text { Usaha } \\
\end{array}$ & Asosiasi usaha & Masyarakat & Wawancara \\
\hline & $\begin{array}{l}\text { - Aturan tentang } \\
\text { komoditi } \\
\text { bersangkutan } \\
\end{array}$ & Aturan & Masyarakat & Wawancara \\
\hline & - Peran Institusi & Peran institusi & Masyarakat & Wawancara \\
\hline & $\begin{array}{l}\text { - Standar komoditi } \\
\text { bersangkutan }\end{array}$ & Standar & Masyarakat & Wawancara \\
\hline & $\begin{array}{l}\text { - Sarana/ fasilitas } \\
\text { pengembangan } \\
\text { komoditi } \\
\text { bersangkutan }\end{array}$ & Sarana & Masyarakat & Wawancara \\
\hline
\end{tabular}

\section{Pengolahan dan Analisis Data}

Penetapan tingkat keunggulan suatu jenis HHBK di lokasi penelitian didasarkan pada Permenhut No.P.21/Menhut-I/2009. Pengolahan dan analisis data yang bersifat kuantitatif yang dikumpulkan dari lapangan dilakukan dengan menggunakan metoda Statistik Non Parametrik (description scoring). Data disusun dalam tabulasi dari tiap wilayah untuk tiap jenis HHBK yang sedang dievaluasi, selanjutnya 
pengolahan data dilakukan dengan tahapan sebagai berikut:

1. Kuantifikasi data pengukuran tiap indikator untuk tiap kriteria dalam data katagorik dan dinyatakan dalam 3 (tiga) selang nilai. Nilai 3 mencerminkan nilai katagori tinggi, 2 menunjukan nilai katagori sedang dan nilai 1 menunjukkan katagori rendah dalam menentukan tingkat keunggulan.

2. Skoring yakni pemberian nilai tiap indikator dengan nilai 3, 2 dan 1 sesuai dengan ukuran standar yang ditetapkan.

3. Penghtiungan Nilai Indikator Tertimbang (NIT) :

NIT suatu kriteria (NITk) adalah hasil bagi antara bobot suatu kriteria $\left(B_{k}\right)$ dengan jumlah indikator pada kriteria tersebut ( $\mathrm{J} / \mathrm{k}$ ) dikali dengan jumlah hasil pembagian antara nilai indikator dengan nilai indikator maksimal (dalam hal ini 3) yang ada dalam kriteria bersangkutan. Secara matematis, perhitungan dilakukan dengan rumusan berikut (Permenhut No. P.21/MenhutII/2009) :

$$
N I T_{k}=\frac{B_{k}}{J I_{k}}\left[\sum_{i=1}^{n} \frac{N_{i}}{N_{i_{\text {max }}}}\right]
$$

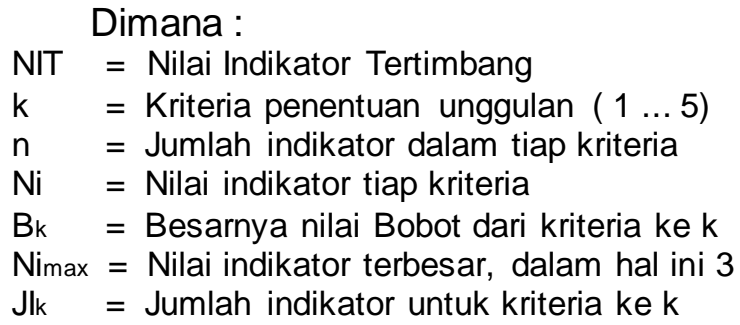

4. Perhitungan Total Nilai Unggulan (TNU) suatu jenis HHBK dilakukan dengan menjumlahkan semua nilai indikator tertimbang dari semua kriteria.

\section{TNU = NIT ekonomi + NIT Biofisik + NIT Kelembagaan + NIT Sosial + NIT Teknologi}

5. Penetapan Nilai Unggulan

Berdasarkan Total Nilai Unggulan (TNU) jenis HHBK dikelompokan ke dalam tiga kelas Nilai Unggulan (NU) sebagai berikut :

a. Nilai Unggulan 1 : jenis komoditas HHBK memiliki nilai TNU : $78-100$

b. Nilai Unggulan 2 : jenis komoditas HHBK memiliki nilai TNU : $54-77$

c. Nilai Unggulan 3 : jenis komoditas HHBK memiliki nilai TNU : $30-53$

6. Penetapan Jenis HHBK Unggulan Penetapan Jenis HHBK Unggulan dilakukan berdasarkan besarnya skor Nilai Unggulan dan 
mempertimbangkan frekuensi penyebaran jenis komoditas tersebut di wilayah penelitian. Selanjutnya Jenis HHBK Unggulan dikelompokkan dalam 3 kelas:

a. Unggulan I (skor 78 - 100)

b. Unggulan II (skor $54-77$ )

c. Unggulan III (skor $30-53$ )

\section{Analisis Data}

Analisis yang dilakukan dalam penelitian ini adalah analisis deskriptif terhadap :

1. Potensi wilayah. yang menggambarkan kondisi bio fisik secara keseluruhan.

2. Potensi masyarakat, yang menggambarkan kondisi sosial ekonomi dan kelembagaan di Kabupaten Kampar.
3. Strategi pengembangan, yang menggambarkan strategi pengembangan HHBK Unggulan di Kabupaten Kampar.

\section{HASIL DAN PEMBAHASAN}

\section{Jenis-Jenis HHBK}

Penelitian dilakukan di wilayah kerja Kesatuan Pengelolaan Hutan Produksi (KPHP) Kampar Kiri, yaitu satu-satunya pengelola hutan di tingkat tapak di Kabupaten Kampar saat ini, meliputi 5 kecamatan, yaitu Kecamatan Kampar Kiri Hulu, Kampar Kiri, Kampar Kiri Hilir, Gunung Sahilan, dan XIII Koto Kampar. Jenis-jenis HHBK yang teridentifikasi biasa dimanfaatkan oleh masyarakat sebagai sumber penghasilan, seperti dirinci pada Tabel 2.

\section{Tabel 2. Jenis-jenis HHBK di Kabupaten Kampar}

\begin{tabular}{|c|c|c|c|c|c|c|c|c|c|c|}
\hline \multirow{2}{*}{$\begin{array}{l}\text { Nama } \\
\text { Desa }\end{array}$} & \multirow[b]{2}{*}{ Kecamatan } & \multicolumn{8}{|c|}{ Jenis-jenis Hasil Hutan Bukan Kayu (HHBK) } & \multirow[b]{2}{*}{ Gaharu } \\
\hline & & Madu & Rotan & Durian & Manggis & Tampui & $\begin{array}{c}\text { Buah } \\
\text { Semangkok }\end{array}$ & Pinang & Petai & \\
\hline $\begin{array}{l}\text { Muara } \\
\text { Selaya }\end{array}$ & Kampar Kiri & $\sqrt{ }$ & $\sqrt{ }$ & $\sqrt{ }$ & $\sqrt{ }$ & $\sqrt{ }$ & $\sqrt{ }$ & $\sqrt{ }$ & $\sqrt{ }$ & \\
\hline Sei Raja & Kampar Kiri & $\sqrt{ }$ & $\sqrt{ }$ & $\sqrt{ }$ & $\sqrt{ }$ & $\sqrt{ }$ & $\sqrt{ }$ & $\sqrt{ }$ & $\sqrt{ }$ & \\
\hline $\begin{array}{l}\text { Sei } \\
\text { Harapan }\end{array}$ & Kampar Kiri & & $\sqrt{ }$ & $\sqrt{ }$ & $\sqrt{ }$ & $\sqrt{ }$ & $\sqrt{ }$ & & & \\
\hline $\begin{array}{l}\text { Koto } \\
\text { Setingkai }\end{array}$ & Kampar Kiri & $\sqrt{ }$ & $\sqrt{ }$ & $\sqrt{ }$ & $\sqrt{ }$ & $\sqrt{ }$ & $\sqrt{ }$ & $\sqrt{ }$ & $\sqrt{ }$ & \\
\hline $\begin{array}{l}\text { Sungai } \\
\text { Sarek }\end{array}$ & Kampar Kiri & $\sqrt{ }$ & $\sqrt{ }$ & $\sqrt{ }$ & $\sqrt{ }$ & $\sqrt{ }$ & $\sqrt{ }$ & $\sqrt{ }$ & $\sqrt{ }$ & $\sqrt{ }$ \\
\hline Ludai & $\begin{array}{l}\text { Kampar Kiri } \\
\text { Hulu }\end{array}$ & $\sqrt{ }$ & $\sqrt{ }$ & $\sqrt{ }$ & $\sqrt{ }$ & $\sqrt{ }$ & $\sqrt{ }$ & $\sqrt{ }$ & $\sqrt{ }$ & \\
\hline Koto Lama & $\begin{array}{l}\text { Kampar Kiri } \\
\text { Hulu }\end{array}$ & & $\sqrt{ }$ & $\sqrt{ }$ & $\sqrt{ }$ & $\sqrt{ }$ & $\sqrt{ }$ & $\sqrt{ }$ & $\sqrt{ }$ & \\
\hline Gema & $\begin{array}{l}\text { Kampar Kiri } \\
\text { Hulu }\end{array}$ & & $\sqrt{ }$ & $\sqrt{ }$ & $\sqrt{ }$ & & & $\sqrt{ }$ & $\sqrt{ }$ & $\sqrt{ }$ \\
\hline $\begin{array}{l}\text { Koto } \\
\text { Gadang }\end{array}$ & $\begin{array}{l}\text { XIII Koto } \\
\text { Kampar }\end{array}$ & $\sqrt{ }$ & $\sqrt{ }$ & $\sqrt{ }$ & $\sqrt{ }$ & $\sqrt{ }$ & $\sqrt{ }$ & $\sqrt{ }$ & & \\
\hline Sahilan & Gunung & $\sqrt{ }$ & & & & & & & & \\
\hline
\end{tabular}




\begin{tabular}{|c|c|c|}
\hline Darusalam & Sahilan & \\
\hline $\begin{array}{l}\text { Gunung } \\
\text { Sahilan }\end{array}$ & $\begin{array}{l}\text { Gunung } \\
\text { Sahilan }\end{array}$ & $\sqrt{ }$ \\
\hline $\begin{array}{l}\text { Rantau } \\
\text { Kasih }\end{array}$ & $\begin{array}{l}\text { Kampar Kiri } \\
\text { Hilir }\end{array}$ & $\sqrt{ }$ \\
\hline Mentulik & $\begin{array}{l}\text { Kampar Kiri } \\
\text { Hilir }\end{array}$ & $\sqrt{ }$ \\
\hline $\begin{array}{l}\text { Gading } \\
\text { Permai }\end{array}$ & $\begin{array}{l}\text { Kampar Kiri } \\
\text { Hilir }\end{array}$ & $\sqrt{ }$ \\
\hline $\begin{array}{l}\text { Sungai } \\
\text { Bungo }\end{array}$ & $\begin{array}{l}\text { Kampar Kiri } \\
\text { Hilir }\end{array}$ & $\sqrt{ }$ \\
\hline
\end{tabular}

Data di Tabel 2 menunjukkan bahwa dari 5 Kecamatan lokasi penelitian, jenis-jenis HHBK lebih banyak terdapat di Kecamatan Kampar Kiri, Kampar Kiri Hulu dan XIII Koto Kampar, bila dibandingkan dengan 2 kecamatan lainnya. Hal tersebut terjadi Karena di ketiga kecamatan tersebut kondisi hutan masih terjaga dengan cukup baik, karena sebagian besar lahan hutan berstatus sebagai kawasan lindung. Sedangkan di Kecamatan Gunung Sahilan dan Kampar Kiri Hilir, sebagian besar hutan berstatus sebagai hutan produksi, yang saat ini dikelola

Tabel 3. Tingkat Keunggulan Masing-Masing Jenis HHBK

\begin{tabular}{|c|c|c|c|c|c|c|c|c|c|}
\hline \multirow{2}{*}{$\begin{array}{l}\text { Tingkat } \\
\text { Unggulan }\end{array}$} & \multicolumn{9}{|c|}{ Jenis HHBK } \\
\hline & Madu & Rotan & Durian & Manggis & Tampui & $\begin{array}{c}\text { Buah } \\
\text { Semangkok }\end{array}$ & Pinang & Petai & Gaharu \\
\hline $\begin{array}{l}\text { Total Nilai } \\
\text { Unggulan (TNU) }\end{array}$ & 55,50 & 48,28 & 57,39 & 51,33 & 48,73 & 45,50 & 53,83 & 53,83 & 44,30 \\
\hline $\begin{array}{l}\text { Nilai Unggulan } \\
\text { (NU) HHBK }\end{array}$ & II & III & II & III & III & III & III & III & III \\
\hline
\end{tabular}

Jenis HHBK yang termasuk dalam tingkat nilai unggulan ke-2, yaitu madu dan durian, dengan Total Nilai Unggulan (TNU) untuk madu sebesar 
55,50 dan 57,39 untuk durian. Jenisjenis HHBK lainnya termasuk dalam kategori tingkat unggulan ke-3 dengan nilai TNU yang bervariasi antara 42,83 sampai dengan 53,83 . Buah pinang dan petai memiliki nilai TNU yang hampir mencapai nilai unggulan ke-ll, yaitu hanya kurang 0,17. Sedangkan madu dan durian hampir mendekati tingkat unggulan ke-l. Buah Durian dan madu sialang merupakan jenis HHBK yang paling potensial untuk diunggulkan di Kabupaten Kampar dengan berbagai alasan, yaitu potensi hasil dan nilai ekonominya yang tinggi, selain itu, aspek konservasi dan sosial dari kedua jenis ini juga termasuk dalam kategori tinggi, yaitu tidak terdaftar dalam CITES Apendix dan pengelolaannya melibatkan sebagian besar masyarakat. Sedangkan kelemahan untuk semua HHBK adalah aspek teknologi, yaitu teknologi budidaya dan teknologi pengolahan hasil yang belum dikuasai oleh masyarakat. Kelemahan lainnya adalah aspek kelembagaan, yaitu belum adalanya kelompok tani atau kelompok pengelolaan HHBK, kecuali untuk madu sialang. Ketiadaan kelembagaan tersebut menyebabkan masyarakat tidak mudah dalam mengajukan bantuan pembinaan dari instansi terkait atau untuk memperluas jangkauan pemasaran.

Peningkatan keunggulan suatu jenis HHBK perlu diupayakan sehingga tujuan meningkatkan kesejahteraan masyarakat dapat tercapai. Strategi pengembangan HHBK telah dilakukan oleh berbagai pihak, salah satu di antaranya adalah yang dirumuskan oleh Zulaifah S. (2006), yang menyebutkan bahwa untuk pengembangan hasil hutan bukan kayu bagi masyarakat adalah dengan cara peningkatan kualitas dan kuantitas, diversifikasi pemanfaatan sumberdaya hutan, pengembangan produk baru, dan memperbaiki harga produk. Hal senada juga disampaikan oleh Gusmailina (2010), yaitu untuk peningkatan kualitas dan kuantitas HHBK melalui penelitian dan pengkajian.

\section{Strategi Pengembangan HHBK}

\section{Unggulan}

Dengan membandingkan pada penelitian yang telah dilakukan oleh Fenopuri (2015) dalam strategi pengembangan HHBK unggulan di Kabupaten Seram bagian Barat, maka strategi pengembangan HHBK unggulan untuk Kabupaten Kampar akan dirumuskan berdasarkan analisis faktor 
lingkungan internal dan eksternal. Strategi pengembangan HHBK akan difokuskan kepada 2 jenis komoditas unggulan, yaitu madu dan durian. Dengan demikian, analisis factor lingkungan internal dan eksternal juga akan difokuskan kepada 2 komuditas tersebut.

\subsection{Faktor Internal dan Eksternal HHBK Madu}

Berdasarkan hasil pengamatan dan wawancara dengan responden, dapat digambarkan beberapa factor internal dan eksternal yang menentukan prioritas strategi pengembangan HHBK madu di Kabupaten Kampar, yaitu :

\section{a. Kekuatan (Strength)}

1. Adanya Potensi produksi madu yang tinggi,

2. Tersedianya SDM yang terampil dalam pemanenan dan pengolahan madu di Kecamatan Gunung Sahilan dan Kampar Kiri Hilir,

3. Sudah adanya kelembagaan dalam pengelolaan madu di Kecamatan Gunung Sahilan dan Kampar Kiri Hilir,
4. Tersedianya sarana transportasi dengan aksesibilitas yang baik.

b. Kelemahan (Weakness),

$\mathrm{Di}$ sisi lain, terdapat juga kelemahan di lingkungan internal, yaitu :

1. Masih

rendahnya keterampilan SDM dalam penguasaan teknologi pemanenan madu secara lestari, dan pengolahan madu di Kecamatan Kampar Kiri, Kecamatan Kampar Kiri Hulu, dan Kecamatan XIII Koto Kampar.

2. Belum adanya kelembagaan dalam pengelolaan dan pemasaran madu di di Kecamatan Kampar Kiri, Kecamatan Kampar Kiri Hulu, dan Kecamatan XIII Koto Kampar.

\section{c. Peluang (Opportunity)}

1. Sudah ada jaringan pemasaran produk madu,

2. Adanya perhatian Pemerintah Daerah Kabupaten Kampar dan LSM dalam pengelolaan madu di Kabupaten Kampar,

3. Adanya permintaan pasar yang terus meningkat 
terhadap madu dan produkproduk dari lebah madu lainnya.

4. Harga madu yang semakin meningkat seiring dengan makin banyaknya permintaan pasar

\section{d. Ancaman (threat)}

1. Terjadinya kebakaran hutan dan lahan setiap musim kemarau, yang mengakibatkan terbakarnya pohon sialang dan tanaman lain yang menjadi sumber pakan lebah madu, serta asap yang ditimbulkan menyebabkan lebah madu terbang jauh meninggalkan pohon sialang

2. Maraknya pencurian madu yang belum sempat dipanen oleh petani madu dan kualitasnya madunya masih rendah (belum matang).

3. Maraknya kasus illegal logging yang juga menebang pohon sialang.

4. Banyaknya konversi lahan hutan menjadi non hutan, sehingga hutan kepungan yang menjadi sumber pakan lebah madu semakin berkurang.

\subsection{Faktor Internal dan Eksternal HHBK Durian}

Sebagaiman HHBK madu, HHBK durianpun menghadapi kondisi lingkungan internal dan eksternal tersendiri yang perlu dipertimbangkan dalam menentukan strategi dalam pengembangan komoditas tersebut, yang dikategorikan sebagai kekuatan, kelemahan, peluang, dan ancaman.

\section{a. Kekuatan (Strength)}

1. Adanya potensi produksi durian yang tinggi di Kabupaten Kampar dan terkenal dengan kualitasnya yang baik.

2. Adanya kemauan masyarakat untuk membudidayakan durian di lahan-lahan yang mereka miliki.

3. Keterlibatan masyarakat desa dalam kepemilikan dan pengelolaan cukup tinggi. 
b. Kelemahan (Weakness)

1. Belum dikuasainya teknologi pengolahan pascapanen dan diversifikasi produk.

2. Pemasaran yang masih bersifat local.

3. Belum adanya kelembagaan dalam pengelolaan tata niaga.

4. Aksesibilitas dan sarana transportasi masih kurang memadai di beberapa daerah.

\section{c. Peluang (Opportunity)}

1. Daya dukung lahan yang masih cukup luas untuk pengembangan budidaya.

2. Adanya permintaan pasar yang cukup tinggi terhadap buah durian dan hasil olahannya.

3. Adanya dukungan dari Pemerintah Daerah dalam pengembangan budidaya durian.

4. Adanya peluang untuk penjualan ke luar daerah dan luar negeri produk olahan buah durian .

\section{d. Ancaman (Threat)}

1. Kebakaran hutan dan lahan yang terjadi setiap musim kemarau menyebabkan terbakarnya pohon durian dan berkurangnya produksi buah.

2. Alih fungsi lahan menjadi perkebunan kelapa sawit menyebabkan berkurangnya lahan untuk budidaya buah durian

3. Masuknya buah durian dari daerah lain ke Provinsi Riau pada saat musim buah durian, menyebabkan harga durian di pasaran menjadi rendah.

Berdasarkan hasil identifikasi terhadap faktor lingkungan internal dan eksternal di atas, maka ditentukan beberapa strategi untuk pengembangan HHBK unggulan di Kabupaten Kampar, yaitu madu dan durian. Strategi yang dirumuskan adalah sebagai berikut :

1. Peningkatan kualitas dan diversifikasi produk (madu dan durian);

2. Peningkatan kualitas SDM pedesaan;

3. Penguatan kelembagaan pedesaan;

4. Fasilitas/pengembangan modal usaha, penanganan pasca panen dan pemasaran 


\section{KESIMPULAN}

Kesimpulan penelitian ini adalah sebagai berikut :

1. Jenis-jenis HHBK di Kabupaten Kampar ada 9 jenis, yaitu : madu (dari Apis dorsata), rotan (Calamus sp), durian (Durio zibethinus), manggis (Garcinia mangostana), tampui (Bacaurea macrocarpa), buah semangkok (Scaphium macropodum), Pinang (Areca catechu), petai (Parkia speciosa) dan gaharu (Aqularia malaccensis).

2. Kelas keunggulan HHBK di Kabupaten Kampar termasuk kelas II dan kelas III.

3. Strategi pengembangan HHBK Unggulan Kabupaten Kampar : 1) Peningkatan kualitas dan diversifikasi produk (madu dan durian); 2) Peningkatan kualitas SDM pedesaan; 3) Penguatan kelembagaan pedesaan; 4) Fasilitas/pengembangan modal usaha, penanganan pasca panen dan pemasaran.

\section{DAFTAR PUSTAKA}

Gusmailina. 2010. Peningkatan mutu pada gaharu kualitas rendah. Jurnal Penelitian Hasil Hutan. Vol. 28
No.3. September 2010. Hal: 291 303.

Moko H. 2008. Menggalakkan hasil hutan bukan kayu sebagai produk unggulan. Informasi Teknis Vol.6 No. 2. September 2008. Hal : $1-6$.

Permenhut RI No P.21/Menhut-II/2009. Tentang Kriteria dan Indikator Penetapan asil Hutan Bukan Kayu Unggulan.

Permenhut RI No P.19/Menhut-I/2009. Tentang Strategi Pengembangan Hasil Hutan Bukan Kayu Nasional.

Zulaifah S. 2006. Pemanfaatan hutan bersama masyarakat untuk pengembangan . 